before referring patients with dyspepsia. Those receiving referrals must ask specific questions and not rely on the information in the letter.

Middlesbrough General Hospital

Middlesbrough TS5 $5 \mathrm{AZ}$

1 Hawkey CJ. Non-steroidal anti-inflammatory drugs and peptic ulcers. Br Med F 1990;300:278-84. (3 February.)

2 Heller SR, Fellows IW, Ogilvie AL, Atkinson M. Non-steroidal anti-inflammatory drugs and benign oesophageal stricture. Br.Med f 1982;285:167-8.

3 Banerjec AK. Enteropathy induced by non-steroidal antiinflammatory drugs. Br.Med f 1989;298:1539-40.

4 Shallcross TM, Heatley RV. Effect of non-steroidal antiinflammatory drugs on dyspeptic symptoms. $\mathrm{Br}$ Med $\mathrm{f}$ 1990; 300:368-9. (10 February.)

5 Steele K, Mills KA, Gilliland AEW, Irwin WG, Taggart A. Repeat prescribing of non-steroidal anti-inflammatory drugs excluding aspirin: how careful are we? Br Med $\mathcal{J}$ 1987;295: 962

\section{Blood transfusion services and the European Community}

SIR, - Dr John D Cash, in his editorial on blood transfusion services and the European Community, 'shows an admirable and proper concern for the public availability of essential and safe processed blood products for therapeutic purposes, but it is a pity that he gives a misleading impression of the intention of the European Commission directive to which he refers.

He states that the "directive seeks to outlaw the paid donor in Europe and to forbid products derived from paid donors from entering Europe," and because of "a heavy and frightening burden on the non-profit making or public sector plasma procurement and fractionation institutions reduce access to new plasma products for the people of the European Community in the 1990s." He implies that the outcome of the directive will be to transfer the processing of voluntarily donated human plasma to commercial processors for gain and that this could possibly inhibit and diminish the supply.

Among other requirements, the directive's aim to ensure that member states take the necessary measures recommended by the Council of Europe and the World Health Organisation to prevent the transmission of infectious disease associated with plasma products, whether produced in the public or the private sector, and that imported materials of a similar nature should meet the same standards. The directive states that "the Community entirely supports the efforts of the Council of Europe to promote voluntary unpaid blood and plasma donation to attain self-sufficiency throughout the Community in the supply of blood products, and to ensure respect for ethical principles in the trade in therapeutic substances of human origin."

Although I disagree with the impression given of the effect of the directive on blood donations, I share Dr Cash's reservations about the attitude of the British government. There are times when the Department of Trade and Industry is the lead department in matters that have a major health interest in Britain. Other European Community governments seem to collaborate more closely with their professions and give greater support to their contributions to committees within the European Commission. I believe that the Department of Health should strengthen its European section and its links with the Department of Trade and Industry to ensure that professional organisations in the United Kingdom are consulted at a time when directives concerned with the provision of health care are in preparation and are still capable of modification.

\section{Northwick Park Hospital}

MICHAEL RINSLER

\section{Harrow HAI 3UJ}

1 Cash JD. Blood transfusion services and the European Com munity. Br Med f 1990;300:481-2. (24 February.)
2 Council Directive of 14 June 1989 extending the scope of Directives $65 / 65 / \mathrm{EEC}$ and $75 / 319 / \mathrm{EEC}$ on the approximation of provisions laid down by the law, regulation or administrative action relating to proprietary medicinal products and lavin down special provisions for medicinal products derived from down special provisions for medicinal products derived from of the European Communities 1989 June 28 . (L 181:4t.

\section{Tryptophan and eosinophilia myalgia syndrome}

SIR,-As Minerva reports, up to mid-February 1269 cases of eosinophilia myalgia syndrome related to the ingestion of tryptophan have been reported in the United States to the Centers for Disease Control.' These cases include 13 deaths, of which one has been confirmed as clearly due to ingestion of tryptophan." The Food and Drug Administration has stopped the sale of tryptophan and urged recall of all tryptophan products containing more than $100 \mathrm{mg}$ per daily dose (FDA, press release, 25 January). Eosinophilia myalgia syndrome has also been reported in France."

Tryptophan is still being prescribed in Britain for depression, though it has been withdrawn here as a non-prescription item. In a letter alerting doctors to eosinophilia myalgia syndrome the Department of Health concluded by recommending that patients should continue to take prescribed tryptophan. So does the Committee on Safety of Medicines. In my opinion this conclusion is unwarranted. How tryptophan products cause eosinophilia myalgia syndrome is not known. 'The contaminants suspected as the "probable" cause and cited by the Committee on Safety of Medicines have been searched for but so far not found; no sources of tryptophan have been identified as safe (FDA, press release, 25 January). There is no compelling medical necessity to expose patients to this potentially serious risk as many bette antidepressants are available. Pending furthe clarification of the pathogenesis of eosinophilia myalgia syndrome tryptophan should not be prescribed.

To gather valid information, good case finding is essential. Cases of eosinophilia myalgia syndrome in the United States went unrecognised until doctors and the public were informed of the hazard and of the clinical picture, after which they looked for it - hence the sudden emergence of 1269 cases in less than four months. Patients who have been taking tryptophan in recent months should be specifically asked about symptoms that must then not be discounted as non-specific somatic complaints, somatoform disorders, etc. The markers to look for are myalgia sufficiently severe to interfere with ordinary activities, eosinophilia over $1 \times 10^{4}$ cells $/ 1$, and absence of other medica conditions that would explain eosinophilia. Symptoms may include rashes, dyspnoea arthralgia, fever, weakness, and oedema of the extremities. ${ }^{*}$ Symptoms do not necessarily or promptly stop when tryptophan is stopped, but often they improve gradually. No one yet knows the course or prognosis of the disorder.

London NW8 9PY

HERTA SILZER

I Anonymous. Views. Br Med J 1990;300:692. (10 March.)

Centers for Disease Control. Eosinophilia-myalgia syndromeNew Mexico. MMWR 1989;38:765-7.

3 Centers for Disease Control. Eosinophilia-myalgia syndrome and L-tryptophan containing products-New Mexico, Minnesota, Oregon and New York. MMWR 1989;38:785-8.

4 Centers for Disèase Control. Update. Eosinophilia-myalgia indrome ascociated with ingestion of L-tryptophan-United States. MMWR 1989:38:842-3.

Cencers for Disease Control. Update as of January 9, 1990. $M M W R$ 1990:39:14-5.

6 Amor B, Rajzbaum G, Poiraudeaux S, Haas C, Cahan A. Eosinophilia myalgia linked with L-tryptophan. Lancel Eosinophil

7 Committee on Safety of Medicines. L-Tryptophan and eosinophilia myalgia syndrome in the USA. Current Problems 1989 No 27:1
8 Kilbourne EM, Swigert LA, Philen RM, et al. Interım guidance on the eosinophilia myalgia syndrome. Ann Intern .Hed 1990:112:85-7.

\section{Management of patients with head injuries}

SIR, - I was pleased to see in the notes section' copy of the South East Thames Regional Health Authority guidelines for the acute management of patients with head injuries. The care of such patients continues to be of great concern, and the best outcome in this group will be achieved by the best possible care from the moment of injury to eventual rehabilitation.

I would like to make a plea for attention also to be paid to the availability of neurosurgical facilities for the definitive care of these patients-both the small group requiring surgery for intracrania haemorrhage and the larger group with diffuse brain injury. Neurosurgical unit facilities in the health authority are located at Brook Hospital at present. Of the 12 patients referred from Kent and Canterbury Hospital in 1989, only seven were able to be accepted at Brook Hospital because of shortage of care facilities in intensive therapy units or shortage of nursing staff. Of these, six were accepted for scanning and, after negative findings in terms of need for operation, were returned the same day for continued care at our district general hospital. The remaining patient underwent surgery and was returned for continued care a month later.

Two patients were children and were therefore admitted to Guy's Hospital because Brook Hospital does not have facilities for children. Both of these were cared for at and subsequently discharged from Guy's Hospital. Two patients were admitted to the Atkinson Morley Unit as Brook Hospital was unable to take them. One was operated on and died, the second was subsequently transferred to St George's Hospital for cardiothoracic care and later returned to Kent and Canterbury Hospital, where he died. The final patient went to Maudsley Hospital as Brook Hospital was unable to take him. He died on the day of transfer. Two further patients, after conversation with the neurosurgical unit, had subdural haemorrhages drained at Kent and Canterbury Hospital.

The prognosis for patients with diffuse brain injury is always poor, but I believe that any improvement in outcome will come not only from improved primary care but also from skilled monitoring and management in a neurosurgica unit. I hope that these services would be made available for all patients in this region.

Kent and Canterbury Hospital.

$S$ C BROOKS

Canterbury CT1 $3 \mathrm{NG}$

Anonymous. Notes. Br Med f 1990;300:546. (24 February.)

\section{Trauma services in a district general hospital}

SIR,-Dr S J Kinny and Mr D H A Jones with their study illustrate how the concept of regiona trauma centres must be adapted for the idiosyncratic variations in geography, population distribution, and hospital services in the United Kingdom.' Their conclusion that the Royal College of Surgeons may have overestimated the require ment for trauma centres, however, requires comment.

The role of the district general hospital in a relatively isolated rural environment would be to recognise early those patients who require the skill available in trauma centres and to stabilise these patients before rapid and safe transfer. The use of 
scoring systems may be valuable in determining which patients require referral to the regional trauma centre. The injury severity score, however, is not an appropriate system for triaging patients prospectively as definitive scoring requires accurate operative or necropsy anatomical data, which cannot be obtained either at the roadside or during initial resuscitation, but is of most value in retrospective audit. The revised trauma score provides guide based on physiological variables (systolic blood pressure, respiratory rate, and Glasgow coma scale), and its value for prospective use to ensure that patients receive treatment at the correct facility is proved.

Although the department studied by Dr Kinny and $\mathrm{Mr}$ Jones was small by United Kingdom standards, with 21000 patient attendances each year, there were 50 deaths from trauma over a period of 12 months. There is no detailed analysis considering whether any of these deaths wer potentially avoidable, but the $30 \%$ preventable death rate from trauma shown elsewhere in the United Kingdom ${ }^{2}$ possibly applied to north Wales. Outcome may be influenced by an improved trauma system based on a regional trauma centre, which, in addition to dealing with acute injury, must also maintain standards of prehospital care throughout the catchment area and provide facilities for intensive care and rehabilitation. Papers based solely on data on mortality from trauma fail to consider the impact of trauma centre management on reducing morbidity and allowing early return to full function; such management may not be provided elsewhere.

The total number of admissions to a trauma centre will be greater than predicted by Dr Kinny and $\mathrm{Mr}$ Jones as there will inevitably be patients who, after full evaluation, are deemed to have been referred inappropriately. In the United States there is concern if these patients constitute less than $10-15 \%$ of the total as this implies that access is denied to other patients who should have been referred. Patients with major trauma represent a small minority of the total number of attendances, and the volume and nature of trauma dealt with a the district general hospital level will still be more than adequate to maintain interest and morale.

Queen Alexandra Hospital

Portsmouth PO6 3LY

1 Kinny SJ, Jones DAH. Trauma service requirements in a district general hospital serving a rural area. $B r M e d f 71990 ; 300 \cdot 504-8$. (24 February.)

2 Anderson ID, Woodford M, de Dombal FT, Irving M. Retrospective study of 1000 deaths from injury in England and Wales. Br Med f 1988;296:1305-8.

SIR,-Dr S J Kinny and Mr D H A Jones have found that very few patients with trauma need to be transferred from a district general hospital in a rural area to a regional trauma centre.' We have compared trauma services in rural Britain and France and found that district general hospitals in Britain offer a much greater depth of experience than is available at district level in France, where regional centres are well established. ${ }^{2}$ For example, in south west France, away from the regional centre in Bordeaux, some 87 oral and maxillofacial surgeons in private practice treat an average of only four patients with jaw fractures annually, whereas in South Western Regional Health Authority all 14 consultants in the specialty treat at least 50 such patients each year. The need for concentration of services at subregional level in France, as occurs in Britain, is clear, though the optimum distribution of British regional or supraregional trauma centres to serve rural and urban populations has yet to be established.

It is inappropriate, however, to organise services only on the basis of European or American experience. Not only does Britain generate fewer patients with major trauma than equivalent popu- lations elsewhere, '? but systems of private fealth care, which are not noted for their control of manpower facilities or continuing education in rural areas, need regional centres to manage a great deal of cases of minor trauma as well as cases of major trauma. Market forces may determine numbers of specialists in a particular area in relation to demand for elective surgery, but the need for trauma services is very different, particularly in poorer areas where accidents and assaults are more likely. Surely a lesson from international comparisons and from the findings of Dr Kinney and Mr Jones is that, supplemented by regional centres, district health authority traum services in rural Britain are a jewel in the crown of the NHS and should be used as a model elsewhere in Europe and in the United States.

JONATHAN SHEPHERD NORMA TIMONEY

Oral and Maxillofacial Unit,

Bristol Dental Hospital and Bristol Royal Infirmary,

Bristol BS1 2LY

1 Kinny SJ, Jones DHA. Trauma services requirements in district general hospital serving a rural area. $\mathrm{Br}$ Med $\mathcal{f}$ 1990:300:504-7 (24 February.)

2 Timoney N, Saiveau M, Pinsolle J, Shepherd JP. A comparative study of maxillo-facial trauma in Bristol and Bordeaux. study of maxillo-facial trauma in

3 Shepherd JP. Violent crime in Bristol: an accident and emergency department perspective. British fournal of Criminology (in press)

SIR, - We commend Mr S J Kinny and Mr D H A Jones for their excellent paper on trauma services requirements in a district general hospital serving a rural area.' This particular form of audit allows an in depth analysis of many of the problems related to management of trauma. We agree with their observations that the demand for acute general and thoracic surgery in patients with trauma is uncommon, but when required it is needed urgently. They have identified that in their hospital they had four multiply injured patients (with an injury severity score $\geqslant 16$ ) in one month and that they transferred three patients for further managemen elsewhere. Their conclusion that trauma centres are not necessary therefore seems inappropriate.

In addition, the area of the country that their study covered is one of the least densely populated areas in the United Kingdom, with little industry and no fast roads. The situation is obviously different in a busy urban area in the midlands with fast roads and plentiful industry. Trauma centres seem to have a considerable role in such an environment. To identify the size of the problem and the number of patients with trauma who have given us cause for concern and thus required special attention we did an analysis of patients with trauma who were admitted to our medical centre.

The centre provides services to the health districts of Nottingham, the northern part of Leicestershire, the eastern part of south Derbyshire, and the southern part of central Nottinghamshire. Its "home" population size is about 800000 , for which it is the local and only accident department. Because it is the base for a regional neurosurgical service it not only attracts patients with head injuries from its own area (these are primarily referred to a consultan neurosurgeon) but also accepts patients with severe head injuries from other districts. With regard to patients with orthopaedic trauma it provides a service for the home population (patients are primarily referred to an orthopaedic surgeon) but because of the special interests of some of the orthopaedic consultants it accepts patients with severe orthopaedic trauma from other districts. The patients analysed were allocated to the most appropriate group, although many had both neurosurgical and orthopaedic injuries, and there was no duplication of cases. An analysis of al patients admitted to the intensive therapy unit after suffering trauma who had an injury severity score of $\geqslant 16$ allows a better understanding of the problem (table).

Although these figures include 13 patients who were injured in the $\mathrm{Ml}$ plane crash (who have been included in the home population figures: two with head injuries and 11 with orthopaedic trauma), they do not include children admitted to the paediatric intensive therapy unit and those patients admitted only to the wards at the hospital and not to the intensive therapy unit.

Currently the channelling of patients to trauma centres is not routine, but, it is already happening to a lesser or greater extent. We believe that the development of trauma centres will change the pattern of referral for only a limited number of patients who are likely to benefit appreciably from the skill that will be concentrated in such centres. It is our view that this is in the best interests of the severely injured patient. These patients, however, are expensive, with regard to both the beds they utilise and the facilities they require, and this needs to be considered carefully in the future. We are pleased to note that the Department of Health has taken positive action in exploring further the concept and practicalities of introducing trauma centres in England and Wales.

W A WALLACE A J BYRNE

\section{JANET K BRIERLEY} N J CLIFTON

University Hospital,

Queen's Medical Centre,

Nottingham NG7 2UH

1 Kinny SJ, Jones DHA. Trauma services requirements in a district general hospital serving a rural area. $B r$ Med $f$ 1990;300:504-8. (24 February.)

\section{Leukaemia and lymphoma among young people near Sellafield}

SIR,-Although Dr Martin Gardner and colleagues have done a fine epidemiological study of increased leukaemia cases around nuclear installations'; their explanation, that the fathers' occupational exposure to radiation is associated with this increase, does not seem to be congruent with several biological and radiobiological principles.

It is implied in the explanation that a dominant mutation is being induced in the fathers' sperm and that this then specifically leads to leukaemia on a probabilistic basis.

A very high frequency of this class of mutations inducing leukaemia would have to be imagined. If there are about 4000 male workers and about 10000 progeny are sampled, then five excess cases

Number and length of admissions of patients with trauma to intensive therapy unit from 1 fanuary 1989 to 31 December 1989

\begin{tabular}{|c|c|c|c|c|}
\hline & \multicolumn{2}{|c|}{ Head injuries } & \multicolumn{2}{|c|}{ Orthopaedic injuries } \\
\hline & $\begin{array}{l}\text { Patients from home } \\
\text { population }\end{array}$ & $\begin{array}{l}\text { Patients from other } \\
\text { districts }\end{array}$ & $\begin{array}{l}\text { Patients from home } \\
\text { population }\end{array}$ & $\begin{array}{l}\text { Patients from other } \\
\text { districts }\end{array}$ \\
\hline $\begin{array}{l}\text { Total No of patients } \\
\text { Mean stay in intensive therapy }\end{array}$ & 20 & 28 & 37 & 5 \\
\hline unit (days) & $\begin{array}{c}4 \cdot 4 \\
88\end{array}$ & $6 \cdot 32$ & $9 \cdot 24$ & $11 \cdot 4$ \\
\hline
\end{tabular}

